\title{
MULTIBAND HANDSET ANTENNA BEHAVIOUR BY COMBINING PIFA AND A SLOT RADIATORS
}

\author{
Jaume Anguera *, Iván Sanz, Josep Mumbrú, Carles Puente \\ Technology and Intellectual Property Rights Dept. Fractus, Barcelona - Spain \\ Jaume.anguera@fractus.com
}

\begin{abstract}
A technique for the handset antenna field combining a PIFA and a slot in presented. The antenna concept features a small footprint and multi-band operation which is required for the new generation of thin profile handset phones.
\end{abstract}

Keywords- PIFA and slot antennas, handset antennas, multi-band operation

\section{INTRODUCTION}

One of the decisive aspects of a portable radio device, such as for instance a hand-held telephone or a wireless device is its volume and size. From the consumer perception, the overall volume, mechanical design, ergonomics and aesthetics of the phone are decisive. For example, there has been an increasing trend in removing external antennas from handsets and substituting them by internal antennas that conveniently fit inside the phone. This avoids the problem of having a protruding part of the phone. External antennas feature several drawbacks: they can break accidentally under mechanical stress or shock and they make the phone more inconvenient and uncomfortable to carry inside a pocket and to extract it outside for operation. For the same reason, there is an increased trend in making thinner phones that can better fit inside a shirt or jacket pocket or a bag or case.

This need in making smaller, thinner phones enters into conflict with the trend of adding more features to the phone. On one hand, phones are increasingly adding components and features such as large color screens, digital cameras, digital music players, digital and analogue radio and multimedia broadcast receivers (FM/AM, DVB-H, DAB, SDARS, DMB and come with a wider range of form factors (bar phones, clamshell phones, flip-phones, slider phones, ...). On the other hand, new cellular and wireless services are being added, which in some cases means that multiband capabilities are required (to feature several standards such as for instance GSM850, GSM900, GSM1800, PCS1900, UMTS) or that other connectivity components (for instance for Bluetooth, IEEE802, WiFi, WiMax, ZigBee, Ultra WideBand). All these trends put an increasing pressure on the antenna features, which need to feature a small footprint, a thin mechanical profile, yet performing efficiently at several frequency bands [1-9]. Therefore, the objective of the paper is to present an antenna technique for handset phones that combines a PIFA and a slot to be integrated into a slow profile multi-band radiator [10].

\section{ANTENNA CONCEPT}

For PIFA antenna used in handset phones, one of the techniques to obtain multi-band behavior is two create several resonant paths [2]. For example, the antenna in Fig. 1a, shows a structure having two branches, one for each operating band. Parasitic elements or increasing height may be used to increase bandwidth. However both techniques increase antenna volume which is especially prohibitive for the new generation of slim phones. Some solutions remove the ground under the antenna area, resulting in a 
monopole of IFA type antenna. For these particular cases, once the ground under the antenna has been removed, the antenna volume can not be reused to place cell-phone components such a camera, vibrator or speaker as they interfere with the antenna, degrading its behavior. The antenna technique presented here, on one hand overcomes the problem of the small bandwidth for low profile PIFA and mitigates the problem of component integration.

The proposed scheme is shown in Fig. 1b: a slot is printed on the groundplane which is fed using a standard mechanism used in most of cell-phones. The same feeding that excites the slot is feeding a PIFA antenna that is placed above the slot. In this investigation, the slot is tuned to be $\lambda_{\mathrm{g}} / 4$ at a frequency in the middle of the range GSM1800-UMTS. On the other hand, the PIFA length is tuned to resonate at GSM900 frequencies. As the PIFA has only one branch that is used for the low band, the space can be reused to create a second path, that is, a new resonant frequency [10]. In this case, a new electrical path has been tuned at $2600 \mathrm{MHz}$ band which is centered at SDMB (Satellite Digital Media Broadcast used in Korea).
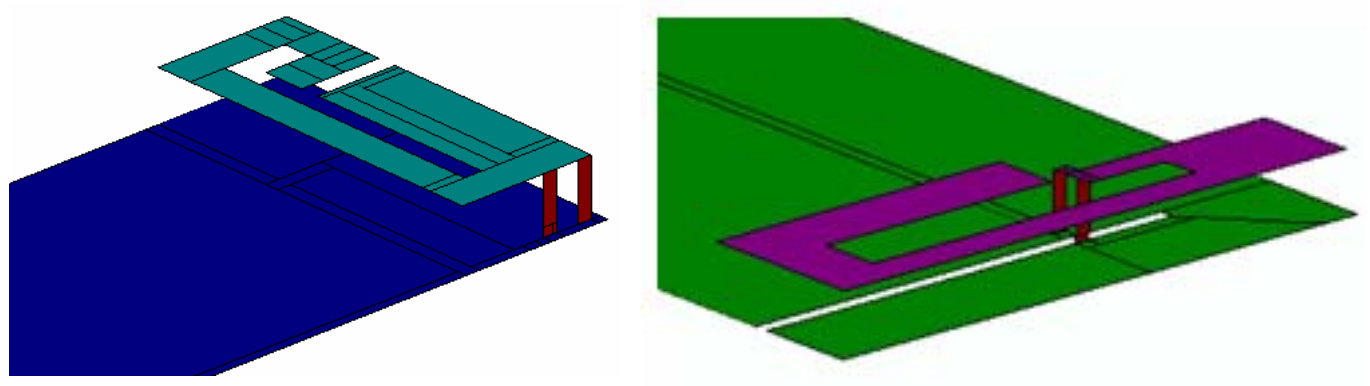

Fig. 1 a) PIFA antenna using two branches for dual-band operation; b) PIFA-slot antenna [10]

\section{RESULTS}

An antenna based on a PIFA-slot concept depicted in Fig. 2(right) has been simulated using the Ie3D MoM commercial software. The PIFA uses two branches; the larger is tuned at GSM900 while the shorted operates at SDMB. The slot is tuned to operate at $2 \mathrm{GHz}$. The antenna is placed on a PCB having $110 \mathrm{~mm} \times 40 \mathrm{~mm}$ size [10].

Once the design is completed, a prototype is built. Real cell-phone components such as camera, battery, display, and back/front cover have been used to determine their influence on the antenna performance. For the sake of brevity, only measures with real components are shown next.
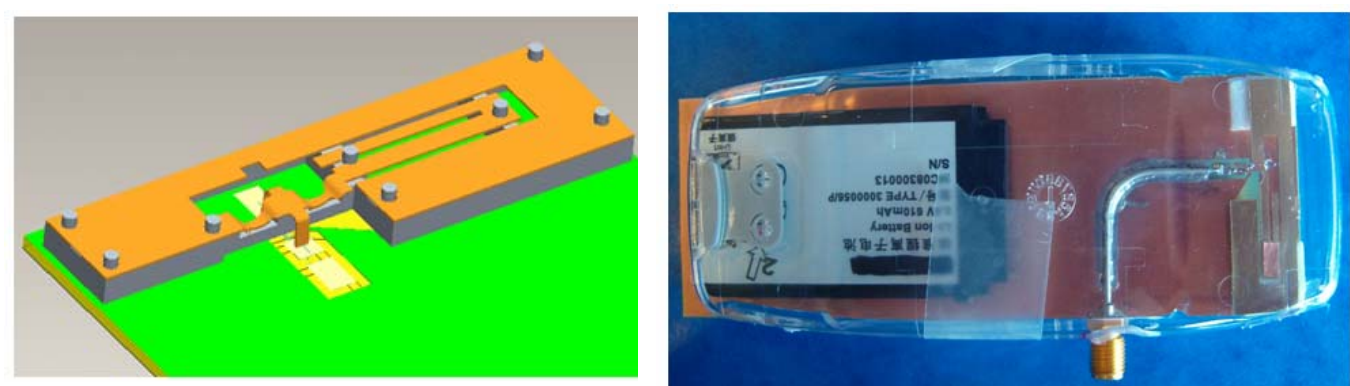

Fig. 2 Left: PIFA-slot antenna scheme. Right: antenna prototype mounted on a PCB populated with battery, camera, display, and front and back covers. Antenna is $39 \mathrm{~mm} x$ $10 \mathrm{~mm} \times 3 \mathrm{~mm}$ (h) 


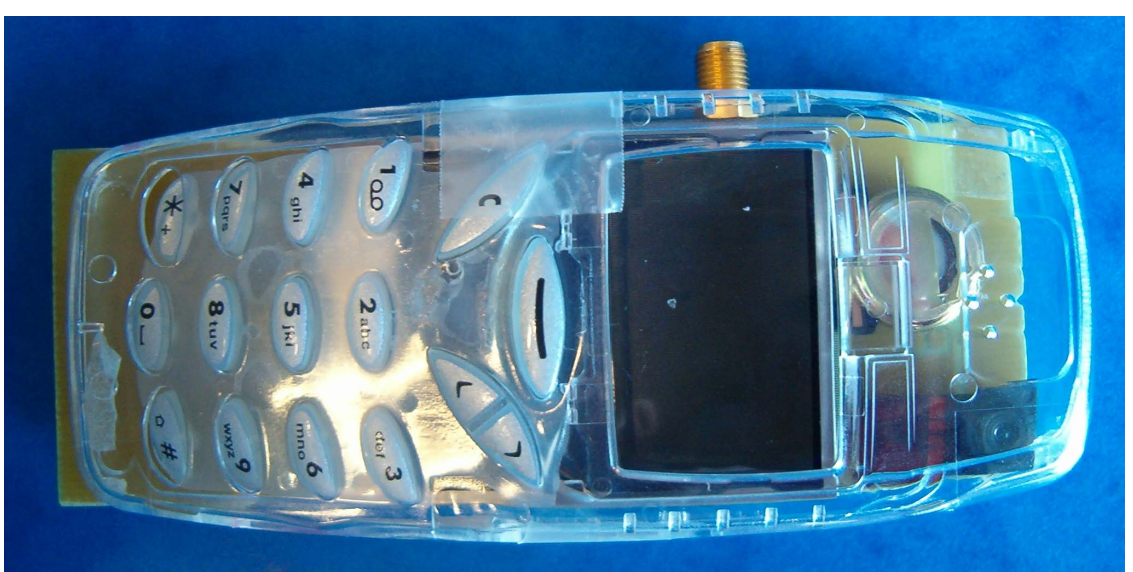

Fig. 3 Top view of the prototype with the front cover, display, camera, and speaker

Antenna return loss and antenna efficiency has been measured as it is shown next for the antenna shown in Fig. 2,3 using real components.

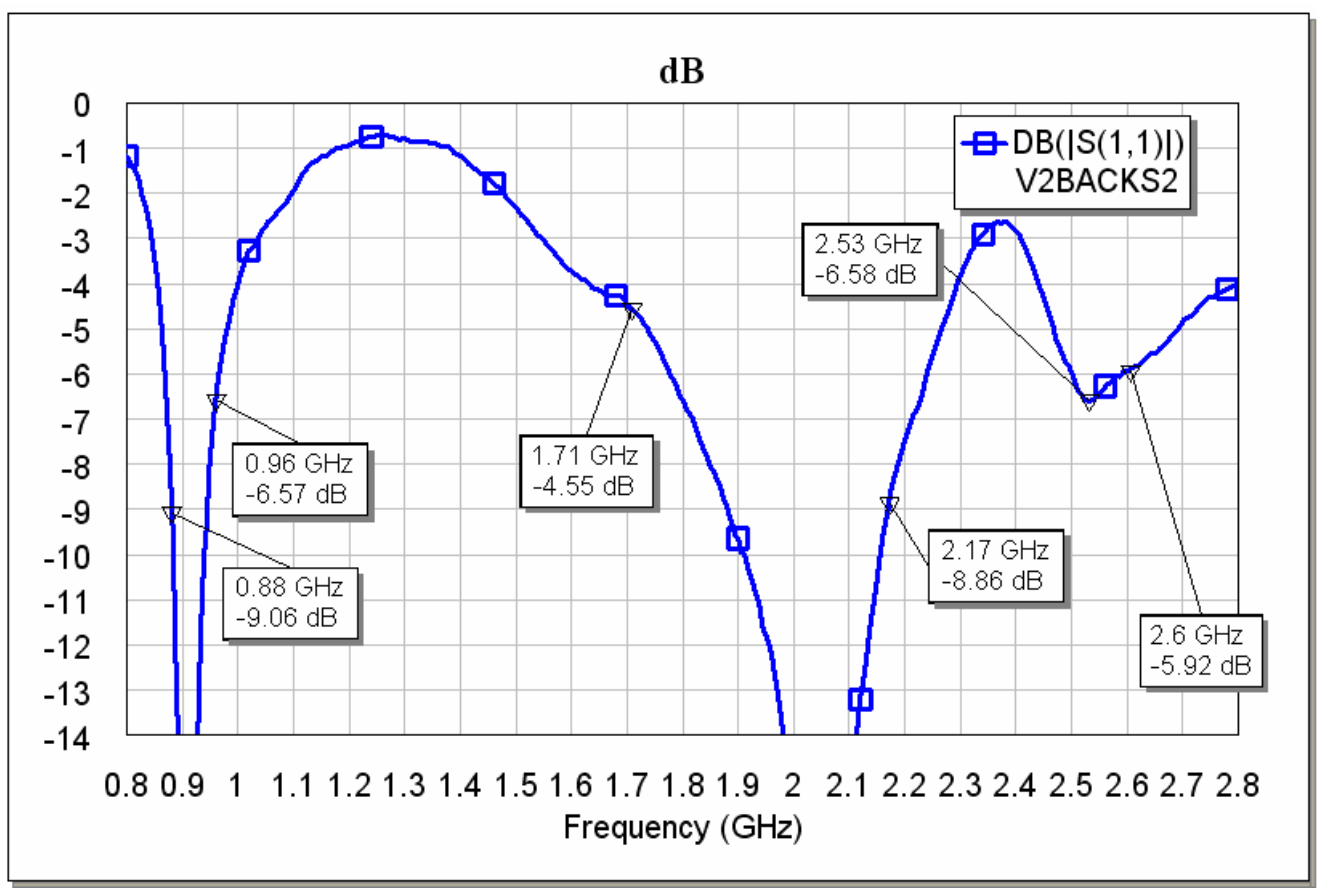

Fig. 4 Free-space return loss

Table. 1 Measured antenna efficiency $\eta_{\mathrm{a}} \cdot \eta_{\mathrm{a}}=\eta_{\mathrm{r}} \cdot\left(1-\left|\mathbf{S}_{11}\right|^{2}\right), \eta_{\mathrm{r}}$ is the radiation efficiency

\begin{tabular}{|c|c|}
\hline Band & Average antenna efficiency [\%] \\
\hline GSM900 (880-890MHz) & 49.8 \\
\hline GSM1800 (1710-1880MHz) & 41.5 \\
\hline GSM1900 (1850-1990MHz) & 53.1 \\
\hline UMTS (1910-2170MHz) & 55.0 \\
\hline SDMB (2630-2655MHz) & 52.3 \\
\hline
\end{tabular}




\section{CONCLUSIONS}

A concept based on a PIFA-slot has been shown to be useful to design multi-band handset antenna for low-profile phones: the antenna size is only $3 \mathrm{~mm}$ above the groundplane.

Thanks to the additional radiator, the PIFA space can be reused to add more bands; for this research, an extra band centered at SDBM has been added.

Results for antenna efficiency taking into account several components (battery, display, speaker, and covers) reveal that this concept is suitable for commercial applications.

\section{ACKNOWLEDGEMENT}

This work has been financed by Fractus.

\section{REFERENCES}

[1] T.Taga and K.Tsunekawa "Performance Analysis of a Built-in Planar Inverted-F Antenna for $800 \mathrm{MHz}$ Band Portable Radio Units", IEEE Trans. Selected Areas in Communication, vol.SAC-5, nº 5 , pp.921-929, June 1987

[2] Patent US701568

[3] D. Manteuffel, A. Bahr, I. Wolff, "Investigation on Integrated Antennas for GSM Mobile Phones", Millennium Conference on Antennas \& Propagation, ESA, AP2000, Davos, Switzerland, April 2000.

[4] T.Y.Wu and K.L. Wong, "On the impedance bandwidth of a planar inverted-F antenna for mobile handsets", Microwave Opt. Tech. Lett. Vol.32, pp.249-251, Feb.20, 2002

[5] P. Vainikainen, J. Ollikainen, O. Kivekäs, and I. Kelander, "Resonator-based analysis of the combination of mobile handset antenna and chassis," IEEE Transactions on Antennas and Propagation, Vol. 50, No. 10, October 2002, pp. 1433-1444.

[6] R. Hossa, A. Byndas, and M. E. Bialkowski, "Improvement of Compact Terminal Antenna Performance by Incorporating Open-End Slots in Ground Plane", IEEE Microwave and Wireless Component Lett. Vol14, ${ }^{\circ} 6$, June 2004

[7] Di Nallo, C., and Faraone, A.: 'Multiband internal antenna for mobile phones', Electron. Lett., 2005, 41, pp. 514-515

[8] B. Jung, J.-S. Lee, M.-J. Park, Y.-S. Chung, F.J. Harackiewicz and B. Lee, "TDMB, AMPS, GSM, DCS, PCS, SDMB internal antenna using parasitic element with switching circuit", Electron. Lett., 2006, 42, pp. 734- 736

[9] J. Anguera, I.Sanz, A.Sanz, A.Condes, D. Gala, C. Puente, and J.Soler, "Enhancing the performance of handset antennas by means of groundplane design". IEEE International Workshop on Antenna Technology: Small Antennas and Novel Metamaterials (iWAT 2006).

New York, USA, March 2006.

[10] Patent Pending WO2006070017 